\title{
Dr Eduard Henoch (1820-1910) of Berlin: pioneer of German paediatrics
}

\author{
Peter M Dunn
}

Eduard Heinrich Henoch was born in Berlin of Jewish parents on 16 July 1829 . His father Joseph was a tax inspector; his mother Sara was a member of the distinguished Romberg family. Henoch trained in medicine with Johann Lukas Schönlein (1793-1864), Professor at the Royal Charite Hospital in Berlin. Together they described the skin rash associated with abdominal colic and arthralgia that is still known as Henoch-Schönlein purpura. He also trained with his uncle Moritz Romberg, Professor of Medicine in Berlin, and was eventually appointed lecturer in internal medicine in 1850. After a spell in private practice, directing paediatric outpatients among the poor (1860-70), he returned to the Charite in 1872 as director of the paediatric clinic and senior lecturer in paediatrics, University of Berlin. In addition to his publications on abdominal diseases, Henoch is perhaps best known for his textbook Lectures on Children's Diseases, first published in 1881 . The fourth edition, in 1888 , was translated and published in English the following year by the great Dr John Thomson of Edinburgh, who wrote in the preface: '... everyone will recognise the extreme and permanent value which must attach to these lectures as the outcome of forty-five years of untiring clinical work by a man of such splendid powers of observation and judgement.' The following extracts are from this source. ${ }^{1}$

\section{On infant mortality}

'Of every 1,000 children born, about 200 die in the first year of life; while the general mortality of the population is about 25 per 1,000 ... Many of these unhappy creatures carry with them from the very beginning the germ of death derived from a diseased mother, and fall victims to congenital debility within the first few days after birth. Many others perish from inherited syphilis; most become atrophic, being reduced by constant diarrhoea; or their numbers are decimated by repeated attacks of bronchitis, with secondary enlargement of the bronchial glands, ending in caseation and general tuberculosis. Many of these children are illegitimate, and not a few of the mothers, as I can assure you from my own large experience, send to the hospital the child which has become a burden to them, not because they wish it to be restored to health, but only in the hope -

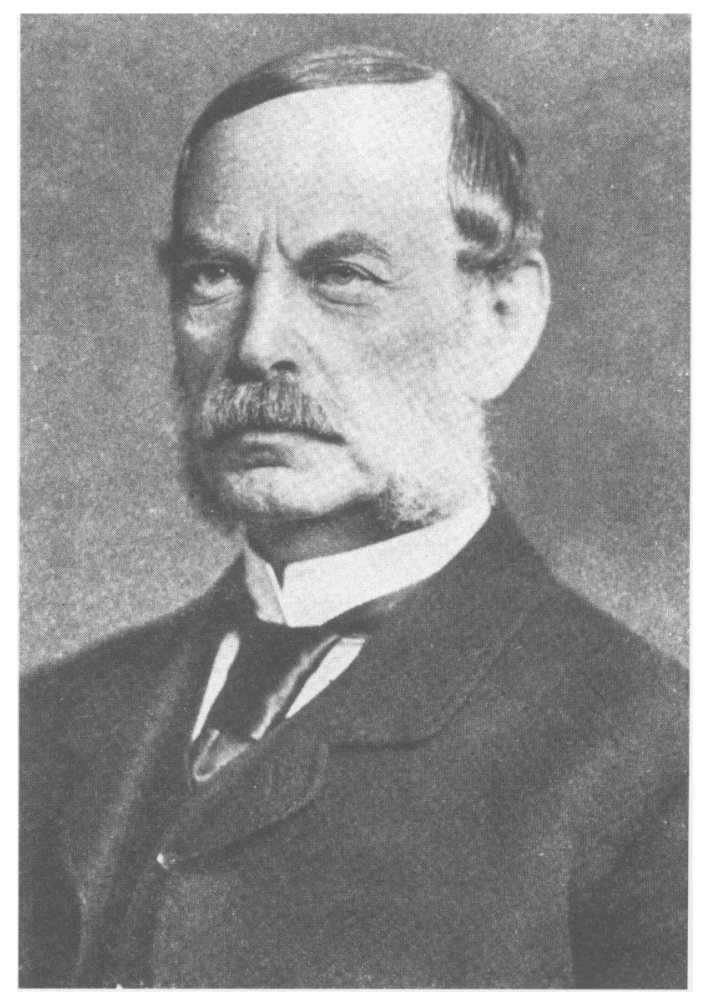

Dr Eduard Henoch (1820-1910).

which is too often justified - that they may be freed from it for ever.'

\section{On congenital sterno-mastoid torticollis}

'You will not very rarely have children brought to you in the first weeks of life who have a hard roundish or elongated uneven swelling on one or other side of the neck, very rarely on both sides, corresponding to the anterior division of the sterno-mastoid muscle. The size of it varies, being sometimes that of a pigeon's egg; often however it is larger and of an elongated form ... The right sterno-mastoid is by far more frequently affected than the other, for out of 30 cases recorded in my journals I find 23 of the right side and only 7 of the left.

The youngest child I have seen with an affection of this kind was three weeks old, the majority were 4-6 weeks, but 4 had reached the ages of 3,5 , and 12 months respectively. In no case did it cause any pain; in most it was discovered quite accidentally while the child was being washed. Less frequently the 
mother's attention was first attracted by the fact that the child's head was not held straight when it was lying, but had always an inclination to one side, usually the right ... The nature of this swelling of the sternomastoid muscle becomes clear to us when we find that almost all the children affected by it have had an abnormal presentation at birth, which either delayed the labour or rendered artificial assistance necessary. Out of 30 cases which I have observed, there had been a breech presentation in 20 , and some force had been used in bringing the labour to a conclusion ... As far as my observation goes, the swelling always takes a favourable course, gradually diminishing, and at last leaving an induration of a varying size in the muscle which scarcely if at all interferes with its functions ... but it cannot be denied that a serious disturbance of function may arise from it and I have every reason to assume this as the original cause in a case of torticollis in a girl six years of age, which dated from the first weeks of life. Also the wry-neck of a boy of seven, which had already been operated on with partial success, three years before, was due to a haematoma of this kind, resulting from a breech presentation.'

Although it is now recognised that the condition is usually very painful in the early weeks and that the aetiology relates primarily to deforming pressure during late fetal life rather than to birth trauma, this was a classic description.

\section{On tetanus neonatorum}

'Most frequently it begins between the 5 th and 9 th days after birth ... Usually the first symptom which strikes those round about the child is the difficulty or impossibility of sucking; every attempt to seize the nipple or bottle with its mouth calls forth a rigid contraction of the muscles of mastication and of the orbicularis oris, which renders sucking impossible. The other facial muscles also take part in the contraction, and the countenance is then disfigured to an extreme degree. At first these spasms occur only paroxysmally, whenever an attempt at sucking is made, and it is still possible to give the child milk with a teaspoon, but after a few hours the symptoms usually become rapidly worse; the fits I have described now occur spontaneously also, without evident cause; in them the forehead gets puckered into furrows, the eyebrows are wrinkled up, the lids fast shut, the lips drawn into a point like a proboscis, and surrounded by radiating folds. Soon the pharyngeal muscles participate, and their contraction interferes with the swallowing of milk poured into the mouth; the attempt to swallow is often accompanied by symptoms of choking with cyanosed visage and arrest of the respiration, which in the intervals between the paroxysms is usually extremely rapid and shallow. If one endeavours to pass a finger into the mouth, the jaws are found to be firmly clenched together owing to rigid contraction of the masseter and temporal muscles; any attempt to overcome this resistance is invariably followed by the accession or aggravation of the convulsive seizures ... usually there is rigidity of the muscles of the neck and back also, with backward retraction of the head and complete immobility of the spinal column, which last one sees most strikingly on grasping the child's body about the middle and supporting it horizontally. The muscles of the upper and lower extremities also often participate more or less. The arms and legs are extended, their muscles hard and unyielding like those of the abdomen, and it is scarcely possible to flex them by force. All these spastic symptoms ... are occasioned or considerably intensified by touching the patient, or by attempts to administer nourishment or enemata. Short convulsive seizures which shoot through the trunk and limbs like electric shocks are also not uncommon. Under these circumstances nourishment by the breast or bottle becomes an impossibility ... The complete interference with the nourishment, combined with the contraction of the muscles above described, which is unquestionably painful, must bring about a rapid sinking ... into a state of stupor, the extremely rapid pulse becomes imperceptible, and death follows either from exhaustion or from asphyxia due to tetanic contractions of the inspiratory muscles. The disease lasts from 24 to 36 hours to 9 days according to the severity of the case.

By far the largest proportion of new-born infants attacked by trismus perish ... Complete recovery however is by no means impossible ... The only remedy, under which I have seen two cases of trismus neonatorum recover, is chloral ... If this medicine cannot be swallowed, one must give it in enemata ... post mortem examination yields nothing characteristic ...

The etiology of trismus would gain considerably in certainty should the view expressed by Beumer (Berl Klin Wochenschr 1887, No 31) be fully confirmed - namely, that here, as in the traumatic tetanus of adults, we have to do with an infection by 'tetanus-bacilli' which gain entrance to the body by the umbilical wound. Dirty hands or dressings are supposed to carry these bacteria 'which are apparently so widely distributed' to the umbilical wound ... Considering the extremely unfavourable results of every method of treatment in this disease, we must insist all the more strongly on careful prophylaxis ...'

Dr Henoch married Helena Louisa Behrens, daughter of a Hamburg merchant in 1854 and they had one child, a daughter. During his lifetime he was recognised as the pioneer of paediatrics in Germany, but sadly did not succeed in establishing a chair in that discipline at the University of Berlin. He retired in 1893 and died in Dresden on 28 August 1910, at the age of 90.

1 Henoch E. Lectures on Children's Diseases. Vols I \& II. 4th edn. Translated by J Thomson. London: the New Sydenham Society, 1889. 